\title{
Efficient nano iron particle-labeling and noninvasive MR imaging of mouse bone marrow-derived endothelial progenitor cells
}

This article was published in the following Dove Press journal:

International Journal of Nanomedicine

10 March 201 I

Number of times this article has been viewed

\author{
Rong Chen* \\ Hui Yu* \\ Zhen-Yu Jia \\ Qun-Li Yao \\ Gao-Jun Teng \\ Jiangsu Key Laboratory of Molecular \\ Imaging and Functional Imaging, \\ Department of Radiology, Zhongda \\ Hospital, Medical School of Southeast \\ University, Nanjing, People's Republic \\ of China \\ *These authors have contributed \\ equally to this work
}

\begin{abstract}
In this study, we sought to label mouse bone marrow-derived endothelial progenitor cells (EPCs) with Resovist ${ }^{\circledR}$ in vitro and to image them using 7.0 Tesla (T) magnetic resonance imaging (MRI). Mouse bone marrow-derived EPCs were cultured in endothelial basal medium with endothelial growth supplement. They were then characterized by immunocytochemistry, flow cytometry, and fluorescence quantitative polymerase chain reaction. Their functions were evaluated by measuring their uptake of 1,1-dioctadecyl-3,3,3,3-tetramethylindocarbocyanine-labeled acetylated low-density lipoprotein (Dil-Ac-LDL), binding of fluorine isothiocyanate (FITC)labeled Ulex europaeus agglutinin (UEA), and formation of capillary-like networks. EPCs were labeled with superparamagnetic iron oxide (SPIO) and their proliferation was then assessed in a water-soluble tetrazolium (WST-8)-based cell proliferation assay. Spin echo sequence (multislice, multiecho [MSME]) and gradient echo sequence (2D-FLASH) were used to detect differences in the numbers of labeled cells by 7.0 T MRI. The results showed that the cultured cells were of "cobblestone"-like shape and positive for CD133, CD34, CD31, von Willebrand factor, kinase domain receptor, and CD45, but negative for F4/80. They could take up Dil-Ac-LDL, bind FITCUEA, and form capillary-like networks on Matrigel in vitro. Prussian-blue staining demonstrated that the cells were efficiently labeled with SPIO. The single-cell T2* effect was more obvious in the 2D-FLASH sequence than in the MSME sequence. Further, there were almost no adverse effects on cell vitality and proliferation. In conclusion, mouse bone marrow-derived EPCs can be efficiently labeled with SPIO and imaged with 7.0-T MRI. They may thus be traced by MRI following transplantation for blood vessel disorders and cancer treatment.
\end{abstract}

Keywords: endothelial progenitor cells, cell labeling, Resovist, magnetic resonance imaging

\section{Introduction}

Endothelial progenitor cells (EPCs) are derived from bone marrow and were first isolated and purified from human peripheral blood by Asahara et al. ${ }^{1}$ EPCs can proliferate independently and differentiate into mature endothelial cells (ECs). ${ }^{2}$ The ability of EPCs to promote revascularization of injured and ischemic tissues means they may be useful in cellular therapies and provide a new approach to therapeutic angiogenesis. EPCs are also promising in cancer therapy as a result of their capacity to invade, migrate within, and incorporate into tumor structures. ${ }^{3}$ Furthermore, EPCs can migrate to ischemic regions of tumor tissue and incorporate into newly formed tumor blood vessels. ${ }^{4,5}$ Cellular therapies targeting cancer growth are currently being tested in preclinical models. ${ }^{6-8}$ Using gene transfer techniques, the therapeutic potential of EPCs may be enhanced. These features make EPCs attractive cellular vehicles for systemic tumor gene therapy. ${ }^{3}$
Correspondence: Gao-Jun Teng Department of Radiology, Zhongda Hospital, Southeast University, Nanjing 210009, \#87 Dingjiaqiao Road, People's Republic of China

Tel +86 2583272121

Fax +86258327 2121

Email giteng@vip.sina.com 
It is essential to trace transplanted stem cells during their migration and differentiation. Of the methods used to track labeled cells, magnetic resonance imaging (MRI) has several advantages, such as high spatial and temporal resolution and good tissue contrast. It is also noninvasive and can be used to track cellular events in vivo in real time. ${ }^{4}$ MR imaging of stem cells is also an emerging strategy for monitoring cell engraftment. ${ }^{5}$ The superparamagnetic iron oxides (SPIOs) are a class of MR contrast agents that generate strong T2-negative contrast in MRI and decrease signal intensity. Resovist ${ }^{\circledR}$ is a kind of SPIO. It acts by reducing the transverse relaxation time (T2) in T2-weighted MRI scans; thus, labeled cells appear as areas of reduced signal intensity. MRI tracking of cells labeled with SPIO has become a valuable technique. ${ }^{9,10}$ In our laboratory, we previously visualized SPIO-labeled EPCs from the peripheral blood of New Zealand rabbits. ${ }^{11,12}$

To our knowledge, no reported study has tested Resovist labeling of mouse bone marrow-derived EPCs and their subsequent imaging by 7.0 Tesla (T) MR. Here, we investigated the characteristics of EPCs in vitro and the efficiency of their labeling with Resovist. In this study, mouse bone marrow-derived EPCs were isolated and cultured. Their identity was confirmed by measuring their expression of cellular surface markers and assessing their function. We subsequently labeled cells with SPIO and imaged them using 7.0 T MR, which has a high signal-tonoise ratio (SNR).

\section{Materials and methods}

\section{Isolation of bone marrow-derived EPCs}

Mononuclear cells were isolated from the bone marrow of C57/BL6 mice. Mice were heparinized before harvesting. Briefly, under aseptic conditions, mouse bone marrow mononuclear cells (BMPCs) were isolated from the femora and tibia by flushing the marrow cavities with RPMI 1640 medium (Clonetics, Sunnyvale, CA). After washing through centrifugation in Histopaque 1077 (400 g, 25 minutes; SigmaAldrich, St. Louis, MO), the cells were resuspended in culture medium supplemented with endothelial basal medium (EBM-2; Clonetics) and EGM-2 SingleQuots endothelial growth supplement (Clonetics) and plated in 6-well culture plates coated with fibronectin (Gibco, Carlsbad, CA). The cells were maintained in a humidified $5 \% \mathrm{CO}_{2}$ atmosphere at $37^{\circ} \mathrm{C}$. The growth medium was replaced every other day. Nonadherent cells were removed after 48 hours and every second day thereafter.

\section{Flow cytometric analysis}

Proportions of cells positive for CD133, CD31, CD34 and KDR, and CD45 and F4/80 were determined by flow cytometry. Cells were washed with phosphate-buffered saline (PBS) and then incubated with fluorine isothiocyanate (FITC)-CD34, PE-CD133, FITC-CD31, PE-KDR, PE-CD45 and FITC-F4/80 primary antibodies (Abcam, Cambridge, MA) for 15-20 min. After washing with PBS, cells were then incubated with secondary antibodies (KPL, Gaithersburg, MD) for 30 minutes. Isotype-matched antibodies were used as controls. All steps were performed at $4^{\circ} \mathrm{C}$. Samples were analyzed using a FACScan instrument (FACSCalibur, FACSCanto; BD Biosciences, Franklin Lakes, NJ) and CellQuest software (BD Biosciences).

\section{Indirect immunofluorescence staining}

Cells were grown on fibronectin-coated glass coverslips and analyzed for the expression of the cellular markers CD31, kinase domain receptor (KDR), and von Willebrand factor (vWF). Briefly, cells mounted on cover-slips were fixed through incubation with cold acetone for 10 minutes, washed with PBS three times and then incubated with primary antibodies for 60 minutes at $37^{\circ} \mathrm{C}$. FITC-labeled secondary antibodies were then added for 30 minutes. PBS without primary antibodies served as negative controls and cell nuclei were stained with 4',6-diamidino-2-phenylindole (DAPI) at the same time. Cells were examined with an inverted Imaginer A1 fluorescence microscope (Carl Zeiss, Jena, Germany).

\section{Phagocytotic activity assay}

Fluorescent chemical detection of EPCs was performed on cells that were adherent after 7 days of culture. Direct fluorescent staining was used to detect the dual binding of FITC-labeled Ulex europaeus agglutinin (UEA) and 1,1dioctadecyl-3,3,3,3-tetramethylindocarbocyanine-labeled acetylated low-density lipoprotein (Dil-Ac-LDL). Cells were first incubated with Dil-ac-LDL $(5 \mu \mathrm{g} / \mathrm{mL})$ at $37^{\circ} \mathrm{C}$ for 2 hours and then fixed through incubation with $4 \%$ paraformaldehyde for 20 minutes. They were subsequently incubated with UEA $(10 \mu \mathrm{g} / \mathrm{mL})$ at $37^{\circ} \mathrm{C}$ for 1 hour. After washing with PBS, the cells were visualized and photographed using a fluorescence microscope and counted at $\times 200$ magnification. Doublepositive cells were considered to be differentiating EPCs.

\section{Tube formation assay in Matrigel}

Matrigel (BD Biosciences) was added to the wells of a 96-well plate ( $45 \mu \mathrm{L} /$ well) and allowed to polymerize for 
30 minutes at $37^{\circ} \mathrm{C}$. Cells $\left(1 \times 10^{4} /\right.$ well in $100 \mu \mathrm{L}$ of EGM- 2$)$ were seeded on top of the Matrigel. ${ }^{13}$ After incubation for 6 hours, the formation of tube-like structures was evaluated using a light microscope. Human umbilical vein endothelial cells (HUVECs) were used as an endothelial control line.

\section{Fluorescence quantitative polymerase chain reaction (PCR)}

Freshly cultured EPCs were harvested and total RNA was isolated using Trizol (Invitrogen, Carlsbad, CA) according to the manufacturer's instructions. Five micrograms of total RNA was reverse-transcribed to cDNA. Quantitative realtime PCR assays were run in triplicates under the following conditions: $95^{\circ} \mathrm{C}$ for 2 minutes; $\left(95^{\circ} \mathrm{C}, 10\right.$ seconds; $60^{\circ} \mathrm{C}$, 30 seconds) $\times 40$ cycles. Primer sequences are shown in Table 1. Data are expressed as $\Delta \Delta \mathrm{ct}=$ average value of $\mathrm{ct}$ (cycle threshold) (object gene) - average value of ct (housekeeping gene).

\section{Labeling of EPCs with nano iron particles}

Resovist (SHU555 A; Schering, Berlin, Germany) has particles about $56 \mathrm{~nm}$ in size and the iron content is $28 \mathrm{mg} / \mathrm{ml}$. Before labeling, Resovist was diluted with endothelial cell growth medium-2 (EGM-2). EPCs were incubated with labeling medium containing $28 \mu \mathrm{g} / \mathrm{mL}$ iron for 24 hours. ${ }^{14}$ They were then washed three times with PBS and harvested using $0.25 \%$ trypsin. A trypan blue exclusion assay was then performed to measure cell viability and to assess the cytotoxicity of iron labeling to EPCs.

\section{Determination of labeling efficiency}

After incubation with SPIO, cells were washed three times with PBS to remove excess iron oxides and then subjected to Prussian blue (PB) staining. Cells were fixed through incubation with $4 \%$ paraformaldehyde for 30 minutes, and then incubated for 30 minutes with $10 \%$ potassium ferrocyanide in $10 \%$ hydrochloric acid, washed, and counterstained with nuclear fast red. Cells containing intracytoplasmic blue granules were considered to be PB-positive. Labeling efficiency was determined by manually counting PB-stained and nonstained cells using a microscope. The percentages of positive cells were determined from the counts from an average of 5-10 high-power fields.

\section{Effect of iron labeling on cell proliferation}

A water-soluble tetrazolium (WST-8)-based colorimetric proliferation assay (Cell Counting Kit-8; KeyGen Biotech, Nanging, China) was performed using SPIO-labeled and unlabeled EPCs according to the manufacturer's instructions. ${ }^{15}$ Cells were trypsinized and resuspended in $500 \mu \mathrm{L}$ of medium. Cells $\left(5 \times 10^{3} /\right.$ well $)$ were plated to fibronectincoated 96-well plates and SPIO was added to certain wells for 24 hours. After washing with PBS, $10 \mu \mathrm{L}$ of CCK-8 was added to each well. After incubation for a further 3 hours at $37^{\circ} \mathrm{C}$, OD values at $450 \mathrm{~nm}$ were measured with an enzymelinked immunosorbent detector (TECAN, Männedorf, Switzerland). This experiment was continued for 10 days and growth curves were constructed for iron-labeled and unlabeled cells.

Table I Primer sequences of PCR

\begin{tabular}{|c|c|c|}
\hline Gene & Primer & Fragment length (bp) \\
\hline MUS-CD3I-F (bpl653) & 5'-TAGCAAGAAGCAGGAAGGACAG-3' & 141 \\
\hline MUS-CD3I-R (bp I794C) & 5'-AATGACAACCACCGCAATGA-3' & \\
\hline MUS-CD3I-P & 5'-FAM-ACAGCCTCCAACAGAGCCAGCAGT-TAMRA-3' & \\
\hline MUS-vWF-F (bp3906) & 5'-GAATTGTCACTGTGATGGTGTGAA-3' & 111 \\
\hline MUS-vWF-R (bp40I7C) & 5'-CTCAACATATGGGGTGGTAGAGC-3' & \\
\hline MUS-vWF-P & 5'-FAM-ACGTGTGAAGCCTGCCAAGAGCC-TAMRA-3' & \\
\hline MUS-KDR-F (bp45I) & 5'-CCAATGCTCAGCGTGATTCT-3' & 93 \\
\hline MUS-KDR-R (bp544C) & 5'-ACCCTGGGAATGGTGAGTGT-3' & \\
\hline MUS-KDR-P & 5'-FAM-ACCGCCGCATTCAGTCACCAATA-TAMRA-3' & \\
\hline MUS-ACTB-F (bp573) & 5'-TCTACGAGGGCTATGCTCTCC-3' & 146 \\
\hline MUS-ACTB-R (bp7|9C) & 5'-CTTTGATGTCACGCACGATTT-3' & \\
\hline MUS-ACTB-P & 5'-FAM-CATCCTGCGTCTGGACCTGGCTG-TAMRA-3' & \\
\hline
\end{tabular}

Abbreviations: PCR, polymerase chain reaction; vWF, von Willebrand factor. 


\section{Magnetic resonance imaging}

Labeled cells were washed in PBS, trypsinized and fixed through incubation with $4 \%$ paraformaldehyde for 30 minutes at $4{ }^{\circ} \mathrm{C}$. Cells were then diluted in $0.3 \%$ agarose to $1 \times 10^{6}, 1 \times 10^{5}$ and $1 \times 10^{4}$ cells $/ \mathrm{mL}$. MR imaging (7.0 T; PharmaScan, Bruker, Germany) was performed using a 23-mm mouse head circular volume coil. The MR sequences were a fast low-angle shot gradient echo sequence (2D-FLASH) and a multislice, multiecho (MSME) sequence. Imaging parameters for 2D-FLASH were as follows: repetition time $(\mathrm{TR})=471.1 \mathrm{~ms}$, echo time $(\mathrm{TE})=7.5 \mathrm{~ms}$, field of view $=3.0 \times 3.0 \mathrm{~cm}^{2}$, matrix $=384 \times 384$, slice thickness $=0.28 \mathrm{~mm}$, spacing layer $=0.43 \mathrm{~mm}$, and flip angle $=13^{\circ}$. The total scan time was 22 minutes, 36 seconds . The parameters for the MSME sequence were: $\mathrm{TR}=2000 \mathrm{~ms}$, $\mathrm{TE}=31.7 \mathrm{~ms}, \mathrm{FOV}=3.85 \times 3.0 \mathrm{~cm}^{2}$, matrix $=512 \times 384$, slice thickness $=0.28 \mathrm{~mm}$, spacing layer $=0.43 \mathrm{~mm}$, flip angle $=180^{\circ}$, and scale time $=9$ minutes, 36 seconds.

\section{Statistical analyses}

All values are expressed as mean \pm standard deviation. Student's $t$-test was used to identify significant differences between groups. Values of $P<0.05$ were considered statistically significant. All tests were performed using SPSS software (version 13.0; SPSS Inc., Chicago, IL).

The contrast analysis of the 2D-FLASH sequence and the MSME sequence involved choosing 10 cells of the corresponding deck in the two sequences, setting the threshold value of the pixel (value $>$ average) with Image J software and counting the number of pixels affected by each cell. Student's $t$-test was used with SPSS. Significance was assumed at $P<0.05$.

\section{Results}

\section{Isolation and characterization of EPCs}

As shown in Figure 1, bone marrow-derived mononuclear cells (MNCs) were cultured on fibronectin-coated plates

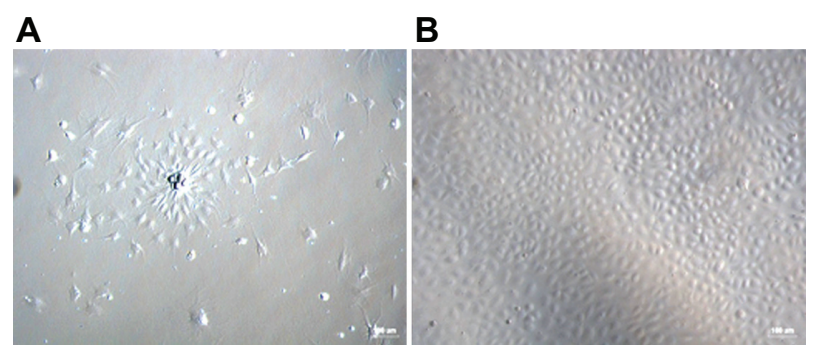

Figure I Morphological changes in mouse bone marrow-derived MNCs. A) Cells changed from globe-like shape to being thin and flat, and then round and fusiform at day 4 (magnification $\times 100$ ). B) At days $7-10$, the cells exhibited a typical long fusiform or "cobblestone" morphology (magnification $\times 100$ ).

Abbreviation: MNCs, mononuclear cells. in the presence of the endothelial cell growth supplement EGM-2. Cells changed from a globe-like shape to being thin and flat at day 4 (left, $\times 100$ ), and they acquired a round, fusiform pebble-like shape at days 7-10 (right, $\times 100$ ).

Results of flow cytometric analyses of bone marrow-derived cells, showing the cells expressed EPCs' characteristic markers CD133, CD34, and KDR. These cells also expressed EC-specific markers CD31 and the pan-leukocyte marker CD45, but did not express F4/80 (Figure 2).

Indirect immunofluorescent staining was performed to further examine the expression of cellular markers in the isolated cells. The results show that the cells expressed CD31, vWF, and KDR $(\times 200$; Figures 3A-D). After 7 days of culture, FITC-UEA and Dil-Ac-LDL double-positive cells were observed by fluorescent microscopy $(\times 200$; Figures $3 \mathrm{E}-\mathrm{H})$.

We used a Matrigel model to examine whether our cultured cells could be induced to form capillary-like structures. The results showed that the EPCs can form a capillary-like structure as the mature ECs in human umbilical vein $(\times 100$; Figure 4$)$.

Fluorescence quantitative PCR was used to analyze marker expression at the mRNA level. Results showed that vWF, KDR, and CD31 mRNA were detectable in EPCs (Figure 5).

\section{Labeling efficiency}

After staining with Prussian blue, iron-labeled cells were found to accumulate iron in the cytosol (Figure 6B) after they were labeled with iron particles (Figure 6A). This indicates that the cells were labeled with iron particles and could be tracked by MRI. As shown in Figure 5C, the average percentage viabilities of the labeled and unlabeled cells were $87.6 \%$ and $92.2 \%$, respectively. There was no significant difference between the groups $(P>0.05)$. The efficiency of SPIO labeling was nearly $100 \%$, as determined by the manual counting of PB-stained and unstained cells using a microscope.

\section{Proliferation potential}

As shown in Figure 7, after 9 days of culture, a cell proliferation assay revealed that there was no statistically significant difference in the growth curves for labeled and unlabeled EPCs between days 2 and $9(P>0.05)$.

\section{MRI results}

MRI showed areas of signal deletion in the MSME sequence (Figures 8A, C) were smaller than in the 2D-FLASH sequence (Figures $8 \mathrm{~B}, \mathrm{D}$ ) and that the signal intensity was higher in the MSME sequence. This indicated that the 
A

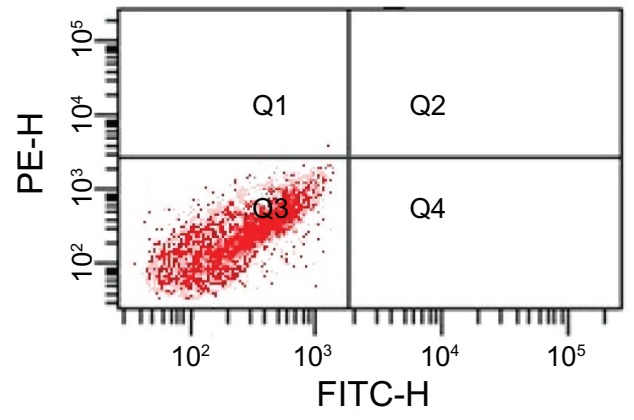

C

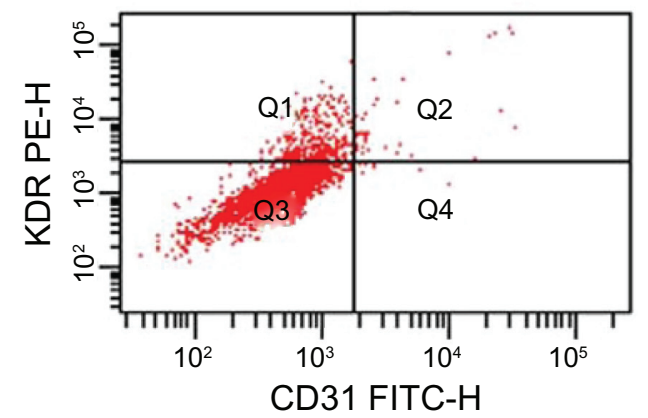

B

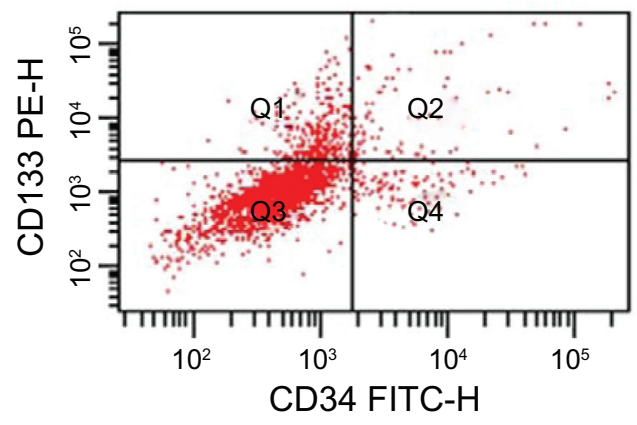

D

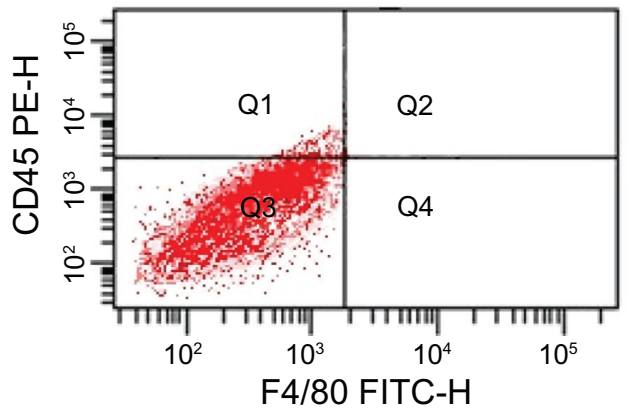

Figure 2 In FACS analyses, EPCs were positive for CDI33 (B, 0.5\%), CD34 (B, 4.1\%), KDR (C, 3.9\%), the mature EC-specific marker CD3I (C, 5.4\%), the pan-leukocyte marker CD45 (D, 2.6\%) and negative for F4/80 (D). Isotype controls were used in the FACS analyses (A).

Abbreviations: EC, endothelial cells; EPCs, endothelial progenitor cells; FACS, fluorescence-activated cell sorting; FITC, fluorescein isothiocyanate.

T2* effect was stronger in 2D-FLASH than in MSME, and that the former was thus more sensitive for detecting single cells. The average numbers of voxels affected by the cells were $20.2 \pm 3.2$ in the MSME sequence and $28.9 \pm 4.0$ in the 2D-FLASH sequence. The difference between the two groups was significant $(P<0.05)$.

\section{Discussion}

EPCs are progenitor cells that can proliferate and differentiate into mature ECs, maintaining normal adult endothelial function through re-endothelialization and angiogenesis., ${ }^{1,16}$ The results of many previous studies have confirmed that EPCs preferentially target tumors and contribute to tumor vasculature. ${ }^{17,18}$ These observations suggesting that EPCs have a predilection for tumor vasculature led to the hypothesis that EPCs could be armed with therapeutic payloads and used as delivery vehicles for tumor gene and/or cell therapy. ${ }^{19,20}$ Although numbers of EPCs in the bone marrow and circulation are very low, they may be readily expanded in vitro. Ex vivo-expanded EPCs have been widely used in experimental studies and may feasibly be used in clinical cell therapies. ${ }^{21}$ The main purpose of this study was to expand EPCs in vitro, to label them with SPIO, and to image them using MRI with a view to possibly using them in tumor gene therapies in the future.

When incubated in vitro with appropriate medium and specific growth factors, such as vascular endothelial growth factor, human fibroblast growth factor-B, and human epidermal growth factor, EPCs have a high proliferation potential and produce colonies of cells expressing EC markers, such as CD34, CD133, and KDR. Key characteristics of EPCs include a "cobblestone" morphology and expression of endothelial marker proteins, as well as the ability to form tube-like structures in vitro, as described previously. ${ }^{22}$ The molecular markers for EPCs are controversial, but the most commonly used ones are CD34, CD133, and KDR. ${ }^{23}$ CD34 and KDR were used by Asahara et $\mathrm{al}^{1}$ as cell markers to isolate cells from peripheral blood before inducing them to form mature ECs. From then on, CD34 and KDR are the most two common markers for isolating EPCs. CD133 was found to discriminate EPCs from mature ECs. So CD34, KDR and CD133 were thought to be the specific molecular markers for isolating EPCs from bone marrow, peripheral blood. CD45 was the pan-leukocyte marker and research ${ }^{24}$ found that the $\mathrm{CD} 45^{\mathrm{dim}}$ fraction contains the prognostic relevant EPC populations. In the present study, isolated mouse 

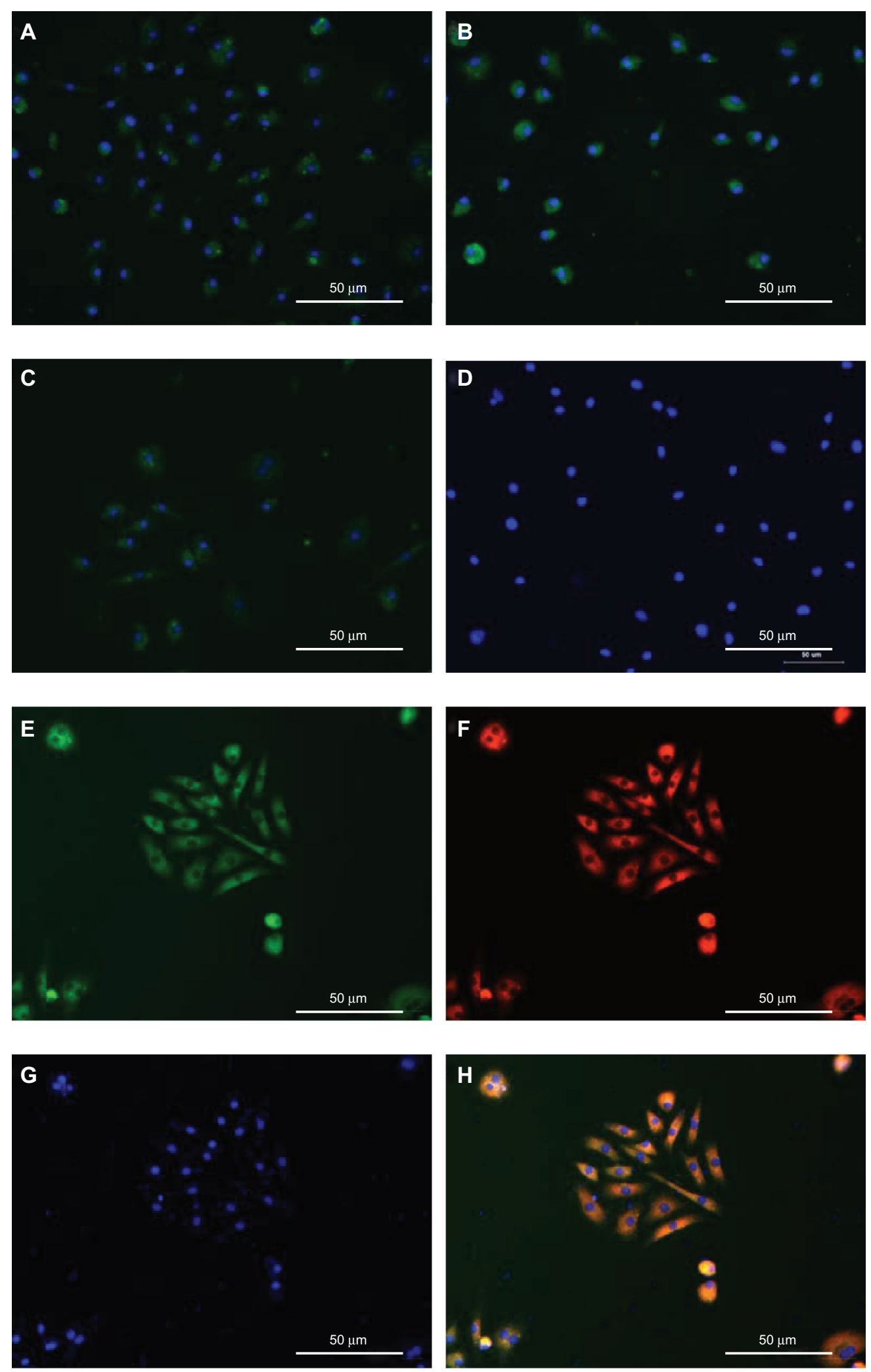

Figure 3 Mouse bone marrow-derived MNCs differentiate into cells with endothelial progenitor cell-like characteristics after expansion in vitro.

Notes: Immunocytochemical analysis of cells cultured for 7 days revealed the expression of the mouse endothelial cell markers CD3I (A), vWF (B), and KDR (C). All antibodies were directly labeled with FITC. Cell nuclei were stained with DAPI. Control cells were incubated with PBS in place of primary antibody (D). These exhibited uptake of acetylated LDL (F) and bound FITC-labeled lectin (E) after 7 days in culture. Cell nuclei were stained with DAPI (G). H) Overlap of these three images. Magnification: $\times 200$.

Abbreviations: DAPI, 4',6-diamidino-2-phenylindole; FITC, fluorescein isothiocyanate; KDR, kinase domain receptor; LDL, low-density lipoprotein; MNCs, mononuclear cells; PBS, phosphate-buffered saline; vWF, von Willebrand factor. 
A

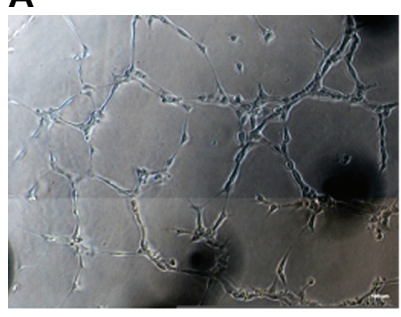

B

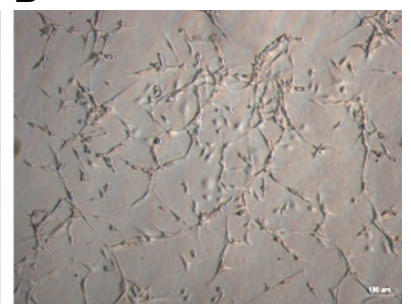

Figure 4 Comparison of the ability to form capillary-like structure between HUVECs and EPCs. A) Capillary-like structure formation in HUVECs as positive control (magnification $\times 100$ ). B) Bone marrow-derived EPCs form the same capillary-like clusters (magnification $\times 100$ ).

Abbreviations: EPCs, endothelial progenitor cells; HUVECs, human umbilical vein endothelial cells.

bone marrow-derived multinuclear cells were cultured in endothelial basal medium with an endothelial growth supplement. The medium was replaced every other day to ensure continuous cytokine stimulation. Within 3-4 days, colonies of cells with various morphologies formed. After approximately 7 days of growth, the cells exhibited a typical endothelial cobblestone morphology and expressed CD31, vWF, CD34, CD45, and KDR, but did not express F4/80 (widely recognized as a marker for mouse macrophages). At the same time, Dil-ac-LDL/FITC-UEA double-positive cells (ie, differentiated EPCs) were identified and counted using a fluorescence microscope. Also, we found that these amplified cells could form tube-like structures on Matrigel in vitro. Collectively, these observations indicated that mice bone marrow-derived MNCs can transdifferentiate into cells with an endothelial phenotype and endothelial functions after stimulation with endothelial growth factors in vitro.

In recent years, some studies have found that monocytes can mimic EPCs by their expression of surface markers and the ability to form cord- and tubular-like structures in vitro. ${ }^{25-27}$ These findings will make monocytes phenotypically indistinguishable from EPCs and may offer a new road for angiogenic therapies.

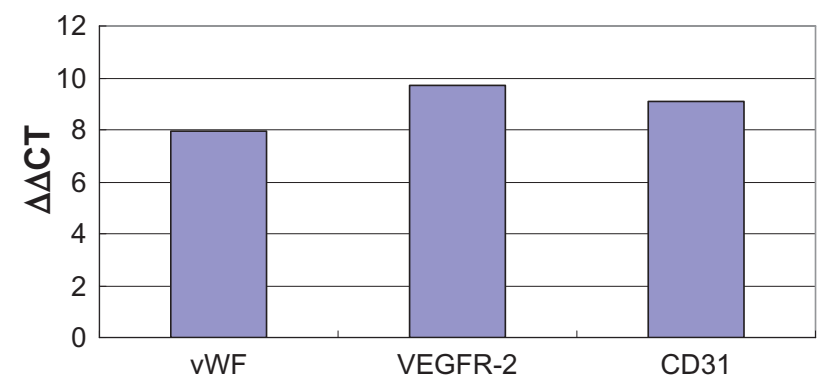

Figure 5 Quantitative PCR analysis of vWF, VEGFR-2, CD3I mRNA levels from mouse bone-marrow derived EPCs.

Abbreviations: EPCs, endothelial progenitor cells; VEGFR-2, vascular endothelial growth factor-2; vWF, von Willebrand factor.
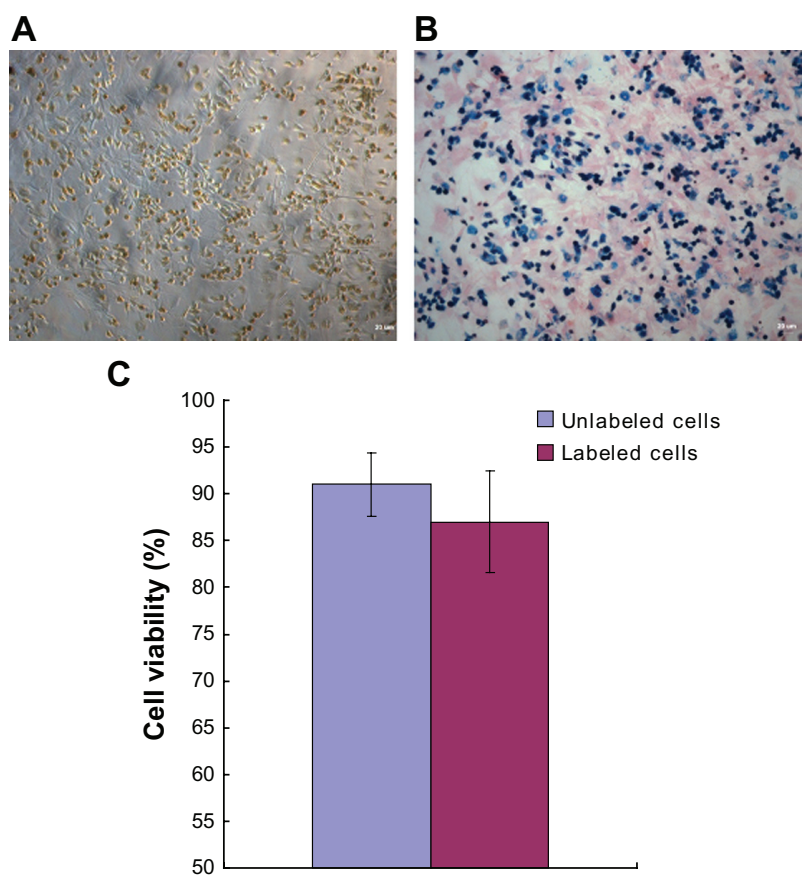

Figure 6 Nano iron particle labeling of endothelial progenitor cells. A) The cytochylema in Resovist-labeled cells contained brown-colored granules. B) Prussian blue staining for iron showed the cytosolic deposition of blue crystals. C) A trypan blue cell viability assay revealed no significant difference between unlabeled cells and iron-labeled cells.

Note: Magnification: $\times 100$.

To date, two iron oxide-based agents have been developed and approved for clinical MRI: ferumoxides (Endorem; distributed in the USA as Feridex) with a particle size of 50-180 nm and ferucarbotran (SHU555 A; Resovist) with a particle size of approximately $60 \mathrm{~nm}$. Resovist is used in both dynamic and delayed imaging. Additionally, the safety profile for Resovist appears more favorable. Studies have shown that

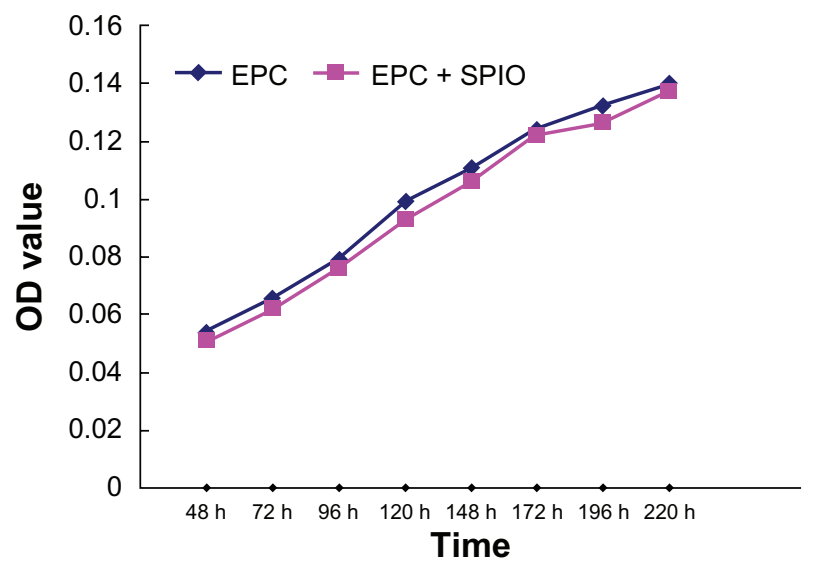

Figure 7 Results of a proliferation assay performed using EPCs.

Notes: The growth curves for SPIO-labeled and unlabeled EPCs were generated from data obtained in a WST-8-based colorimetric proliferation assay. The two kinds of cells displayed similar growth rates.

Abbreviations: EPCs, endothelial progenitor cells; OD, ; SPIO, superparamagnetic iron oxide; WST-8, water-soluble tetrazolium. 

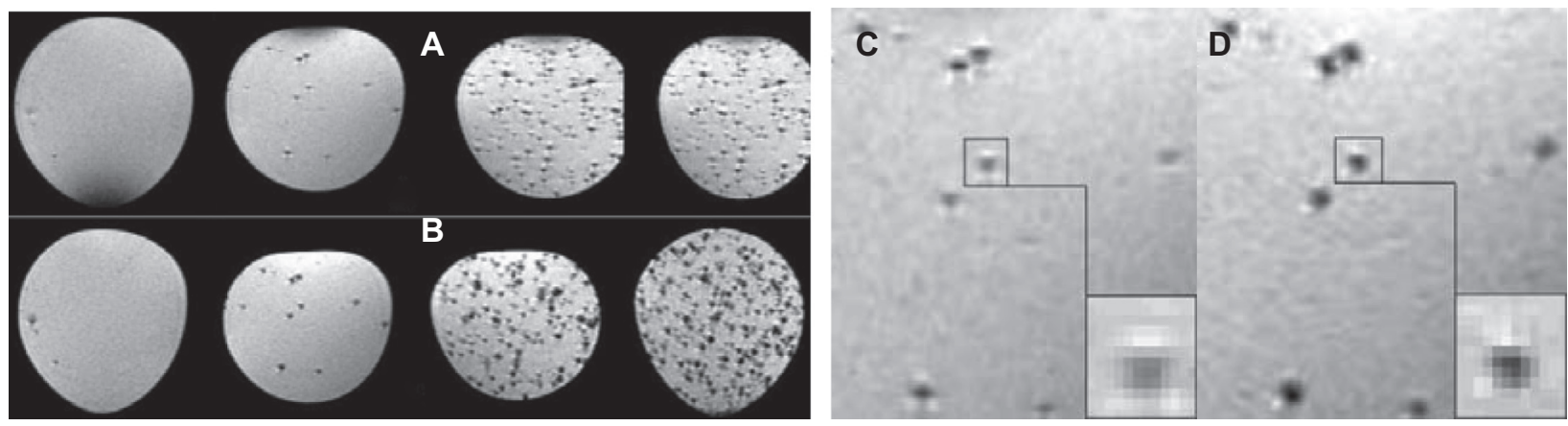

Figure 8 MR images of nano iron particle-labeled single cells in the MSME (A, C) and 2D-FLASH (B, D) sequences. The 2D-FLASH sequence was more sensitive than the MSME sequence under conditions of identical slice thickness and resolving power.

Abbreviations: 2D-FLASH, gradient echo sequence; MR, magnetic resonance; MSME, multislice, multiecho.

labeling multipotent adult progenitor cells (MAPCs) and neural precursor cells (NPCs) with ferucarbotran (Resovist, Schering AG) at a concentration of $25 \mu \mathrm{g} \mathrm{Fe} / \mathrm{mL}$ for 24 hours was $100 \%$ efficient and did not impair cell survival or sphereforming ability or compromise multipotency. ${ }^{14,28}$ In the present study, we have, for the first time, labeled mouse bone marrow-derived EPCs with Resovist, and have described a simple in vitro protocol for labeling EPCs of mouse origin that does not impair proliferative ability. We showed, through Prussian blue staining, that labeling of cells with Resovist under the same conditions was almost $100 \%$ effective. Growth curve analysis further showed that SPIO labeling had no effect on cell vitality or proliferation.

MRI has been used for noninvasive imaging of low numbers of SPIO-labeled cells following transplantation. ${ }^{28}$ The gradient magnetic fields produced in small areas by single labeled cells leads to T2* effect increases. Thus, MRI could track labeled cells more easily because the areas of signal deletion $(200 \mu \mathrm{m})$ were bigger than those of the unlabeled cells $(20 \mu \mathrm{m}) .{ }^{29}$ We have demonstrated that the punctiform signal deletion was caused by labeled cells. ${ }^{30}$ The 2D-FLASH sequence was more sensitive with the uneven magnetic field than the MSME sequence and thus better for detecting individual labeled cells.

To summarize, in this study we successfully cultured, labeled, and MR imaged EPCs. Additionally, we showed that SPIO labeling had almost no adverse effect on cell activity or proliferation. Magnetic labeling of cells with SPIO may be useful for monitoring the temporal and spatial migration of EPCs into tissues and may facilitate the development of cell-based gene therapies for carcinomas.

\section{Acknowledgment}

This work was supported by grants from the National Natural Science Foundation of China (No.30870703, 30910103905).

\section{Disclosure}

The authors report no conflicts of interest in this work.

\section{References}

1. Asahara T, Murohara T, Sullivan A, et al. Isolation of putative progenitor endothelial cells for angiogenesis. Science. 1997;275(5302): 964-967.

2. Zhang W, Zhang G, Jin H, Hu R. Characteristics of bone marrowderived endothelial progenitor cells in aged mice. Biochem Biophys Res Commun. 2006;348(3):1018-1023.

3. Debatin KM, Wei J, Beltinger C. Endothelial progenitor cells for cancer gene therapy. Gene Ther. 2008;15(10):780-786.

4. Unger EC. How can superparamagnetic iron oxides be used to monitor disease and treatment? Radiology. 2003;229(3):615-616.

5. Reimer P, Balzer T. Ferucarbotran (Resovist): a new clinically approved RES-specific contrast agent for contrast-enhanced MRI of the liver: properties, clinical development, and applications. Eur Radiol. 2003; 13(6):1266-1276.

6. Kaushal S, Amiel GE, Guleserian KJ, et al. Functional small-diameter neovessels created using endothelial progenitor cells expanded ex vivo. Nat Med. 2001;7(9):1035-1040.

7. Rafii S, Lyden D. Therapeutic stem and progenitor cell transplantation for organ vascularization and regeneration. Nat Med. 2003; 9(6):702-712.

8. Young PP, Vaughan DE, Hatzopoulos AK. Biologic properties of endothelial progenitor cells and their potential for cell therapy. Prog Cardiovasc Dis. 2007;49(6):421-429.

9. Arbab AS, Janic B, Knight RA, et al. Detection of migration of locally implanted $\mathrm{AC} 133+$ stem cells by cellular magnetic resonance imaging with histological findings. FASEB J. 2008;22(9):3234-3246.

10. Li Z, Suzuki Y, Huang M, et al. Comparison of reporter gene and iron particle labeling for tracking fate of human embryonic stem cells and differentiated endothelial cells in living subjects. Stem Cells. 2008; 26(4):864-873.

11. Mai XL, Ma ZL, Sun JH, Ju SH, Ma M, Teng GJ. Assessments of proliferation capacity and viability of New Zealand rabbit peripheral blood endothelial progenitor cells labeled with superparamagnetic particles. Cell Transplant. 2009;18(2):171-181.

12. Ma ZL, Mai XL, Sun JH, et al. Inhibited atherosclerotic plaque formation by local administration of magnetically labeled endothelial progenitor cells (EPCs) in a rabbit model. Atherosclerosis. 2009;205(1): $80-86$.

13. Nagano M, Yamashita T, Hamada H, et al. Identification of functional endothelial progenitor cells suitable for the treatment of ischemic tissue using human umbilical cord blood. Blood. 2007;110(1): $151-160$.

14. Agbulut O, Mazo M, Bressolle C, et al. Can bone marrow-derived multipotent adult progenitor cells regenerate infarcted myocardium? Cardiovasc Res. 2006;72(1):175-183. 
15. Imamura M, Kanematsu A, Yamamoto S, et al. Basic fibroblast growth factor modulates proliferation and collagen expression in urinary bladder smooth muscle cells. Am J Physiol Renal Physiol. 2007; 293(4):F1007-F1017.

16. Reyes M, Dudek A, Jahagirdar B, Koodie L, Marker PH, Verfaillie CM. Origin of endothelial progenitors in human postnatal bone marrow. J Clin Invest. 2002;109(3):337-346.

17. Sharpe EE 3rd, Teleron AA, Li B, et al. The origin and in vivo significance of murine and human culture-expanded endothelial progenitor cells. Am J Pathol. 2006;168(5):1710-1721.

18. Yurugi-Kobayashi T, Itoh H, Yamashita J, et al. Effective contribution of transplanted vascular progenitor cells derived from embryonic stem cells to adult neovascularization in proper differentiation stage. Blood. 2003;101(7):2675-2678

19. Ii M, Nishimura H, Iwakura A, et al. Endothelial progenitor cells are rapidly recruited to myocardium and mediate protective effect of ischemic preconditioning via "imported" nitric oxide synthase activity. Circulation. 2005;111(9):1114-1120.

20. Ceradini DJ, Kulkarni AR, Callaghan MJ, et al. Progenitor cell trafficking is regulated by hypoxic gradients through HIF-1 induction of SDF-1. Nat Med. 2004;10(8):858-864.

21. Zimmet JM, Hare JM. Emerging role for bone marrow derived mesenchymal stem cells in myocardial regenerative therapy. Basic Res Cardiol. 2005;100(6):471-481.

22. Liu JW, Dunoyer-Geindre S, Serre-Beinier V, et al. Characterization of endothelial-like cells derived from human mesenchymal stem cells. $J$ Thromb Haemost. 2007;5(4):826-834.
23. Kudo FA, Nishibe T, Nishibe M, Yasuda K. Autologous transplantation of peripheral blood endothelial progenitor cells (CD34+) for therapeutic angiogenesis in patients with critical limb ischemia. Int Angiol. 2003; 22(4):344-348.

24. Schmidt-Lucke C, Fichtlscherer S, Aicher A, et al. Quantification of circulating endothelial progenitor cells using the modified ISHAGE protocol. PLoS One. 2010;5(11):e13790.

25. Schmeisser A, Garlichs CD, Zhang H, et al. Monocytes coexpress endothelial and macrophagocytic lineage markers and form cord-like structures in Matrigel under angiogenic conditions. Cardiovasc Res. 2001;49(3):671-680.

26. Rohde E, Malischnik C, Thaler D, et al. Blood monocytes mimic endothelial progenitor cells. Stem Cells. 2006;24(2):357-367.

27. Rehman J, Li J, Orschell CM, March KL. Peripheral blood "endothelial progenitor cells" are derived from monocyte/macrophages and secrete angiogenic growth factors. Circulation. 2003;107(8): 1164-1169.

28. Neri M, Maderna C, Cavazzin C, et al. Efficient in vitro labeling of human neural precursor cells with superparamagnetic iron oxide particles: relevance for in vivo cell tracking. Stem Cells. 2008;26(2): 505-516.

29. Himmelreich U, Aime S, Hieronymus T, et al. A responsive MRI contrast agent to monitor functional cell status. Neuroimage. 2006; 32(3):1142-1149.

30. Jia ZY, Zhang HY, Chen J, Teng GJ. [Imaging of magnetically labeled single-cell by 7.0 T MR]. Zhonghua Yi Xue Za Zhi. 2010;90(21): 1467-1471.
International Journal of Nanomedicine

\section{Publish your work in this journal}

The International Journal of Nanomedicine is an international, peerreviewed journal focusing on the application of nanotechnology in diagnostics, therapeutics, and drug delivery systems throughou the biomedical field. This journal is indexed on PubMed Central,

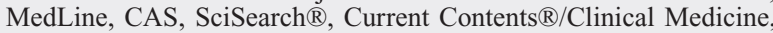

\section{Dovepress}

Journal Citation Reports/Science Edition, EMBase, Scopus and the Elsevier Bibliographic databases. The manuscript management system is completely online and includes a very quick and fair peer-review system, which is all easy to use. Visit http://www.dovepress.com/ testimonials.php to read real quotes from published authors 